\title{
酸性堆積軟岩の風化過程における化学的・生化学的特性
}

\author{
奥 村 充 司* 山田 幹 雄* \\ 佐 野 博 昭** 前 川 晴 義***
}

\section{Chemical and Biochemical Characteristics of Acid Sedimentary Soft Rock in the Process of Weathering}

\author{
by \\ Mitsushi Okumura ${ }^{*}$, Mikio Yamada ${ }^{*}$, Hiroaki Sano ${ }^{* *}$ and Haruyoshi MaEKAWA ${ }^{* * *}$
}

\begin{abstract}
Recently, the acid sedimentary soft rock that caused a collapse of the cutting ground has appeared in the surface with the road construction and the estate development. The acid soil at construction, however, must be effectively utilized as the land reclamation.

The purposes of this study are to verify the importance of the biochemical oxidation of pyrite in the weathering process and to investigate the optimum $\mathrm{pH}$ condition for faster oxidation than in nature. First, $\mathrm{pH}$, sulfate content and pyrite remaining in the acid soil that collected in the field were measured. When the ratio of pyrite remaining in the soil was less than 70 percents, $\mathrm{pH}$ was also lowered with the decrease in the pyrite remaining. Then, samples that added the commercial pyrite or sulfur powder were sterilized by the autoclave in order to clarify the biochemical characteristics of the acid sedimentary soft rock in the weathering. The result showed that sulfate ion was detected only in non-sterilized samples at $\mathrm{pH}$ below 3.5. On the other hand, sulfur powder was hardly converted at $\mathrm{pH}$ above 2.5. Therefore, it was confirmed that ferrous iron oxidation, given as $\mathrm{Fe}^{2+}+1 / 4 \mathrm{O}_{2}+\mathrm{H}^{+} \rightarrow \mathrm{Fe}^{3+}+1 / 2 \mathrm{H}_{2} \mathrm{O}$ was the most important process in the biochemical oxidation of pyrite and its optimum $\mathrm{pH}$ was 2.5-3.5.
\end{abstract}

Key words : Sedimentary soft rock, Acid sulfate soil, Pyrite, Ferrous iron, Ferric iron, Sulfate ion, pH

\section{1 緒言}

近年, 道路建設や丘陸地の宅地開発など大規模な土地 改変が行われ，地表下 $20 \sim 30 \mathrm{~m}$ 以内に存在する潜在的 酸性発生土（以下, 酸性土と称す）あるいは堆積軟岩が 地表に出現している。このような土は，切土地盤の盤膨 れや法面の緑化不良などの問題を引き起こしている.1)

著者らは,これまで石川県河北郡津幡地区に産する酸 性土に着目し，土の工学的特性に関しての知見 ${ }^{2)}$, 3) を蓄 積してきた。また，道路法面の酸性移行過程で地すべり 災害が発生したことを報告し，この現象を道路建設によ つて法面として露出した黄鉄鉱を含む地層の化学的およ び生化学的風化が原因と推定した.4)黄鉄鉱を含む堆積泥 岩は全国各地の第三紀層に多く見られ，当地付近で酸性 土も産出されることから便宜上酸性堆積軟岩と称し, 只 の破砕片は工学的に酸性土と同様に取り扱う。

一方，平成 12 年に建設工事に係る資材の再資源化等 に関する法律が公布され, 酸性土は建設副産物の中の建 設発生土すなわち土地造成の目的となる土砂として有効 に活用される機会が増加している，そこで，酸性土の工 学的, 化学的特性の時間的変化を予測し, 速やかに生化 学的安定化を促し，また，実際の施工に向けては，安定 処理後の再酸性化を抑止可能な強酸性土の安定处理材の
最適配合を設計することが重要である。そのため，予め 建設発生土の黄鉄鉱含有の有無を検查し，然るべき対応 策を講ずる必要性が指摘されている.1),6)すなわち，

1）建設発生土として有效活用するために化学的・生化 学的安定処理すなわち短期間で酸化を完了させる技術

2）酸性化した土の安定処理法，を挙げることができる.

本論文は，上記 1）の課題に焦点を絞り，主要な生化 学的酸化メカニズムとその最適 $\mathrm{pH}$ 条件を検討すること を目的に, 酸性堆積軟岩の化学的, 生化学的風化特性を 特徴付ける $\mathrm{pH}$, 硫酸イオン, 2 価鉄打よび 3 価鉄を指標 として, 種々の室内実験を行った結果について述べる.

\section{2 黄鉄鉱の酸化機構}

黄鉄鉱の酸化に関する反応を式 (1)～(5) に示す??

$$
\begin{aligned}
& \mathrm{FeS}+7 / 2 \mathrm{O}_{2}+\mathrm{H}_{2} \mathrm{O} \rightarrow 2 \mathrm{SO}_{4}^{2-}+\mathrm{Fe}^{2+}+2 \mathrm{H}^{+} \\
& \mathrm{FeS}_{2}+1 / 2 \mathrm{O}_{2}+2 \mathrm{H}^{+} \rightarrow \mathrm{Fe}^{2+}+2 \mathrm{~S}+\mathrm{H}_{2} \mathrm{O} \\
& 2 \mathrm{~S}+3 \mathrm{O}_{2}+2 \mathrm{H}_{2} \mathrm{O} \rightarrow 2 \mathrm{SO}_{4}^{2-}+4 \mathrm{H}^{+} \\
& \mathrm{Fe}^{2+}+1 / 4 \mathrm{O}_{2}+\mathrm{H}^{+} \rightarrow \mathrm{Fe}^{3+}+1 / 2 \mathrm{H}_{2} \mathrm{O} \\
& \mathrm{FeS}_{2}+14 \mathrm{Fe}^{3+}+8 \mathrm{H}_{2} \mathrm{O} \rightarrow 15 \mathrm{Fe}^{2+}+2 \mathrm{SO}_{4}^{2-}+16 \mathrm{H}^{+}
\end{aligned}
$$

ここで, 化学的酸化とは黄鉄鉱が酸化䨌囲気にある水 分と反応して 2 価の鉄イオンを生じる反応で，式 (1)，式

$\dagger \quad$ 原稿受理 平成 15 年 4 月 9 日 $\quad$ Received Apr. 9, 2003

* 正 会 員 福井工業高等専門学校環境都市工学科 †916-8507 鯖江市下司町, Dept. of Civil Eng., Fukui National College of Tech., Geshi-cho, Sabae, 916-8507

** 正会員 大分工業高等専門学校土木工学科 ₹870-0152 大分市大字牧, Dept. of Civil Eng., Oita National College of Tech., Maki, Oita, 870-0152 *** 金沢工業大学土木工学科 $\mp 921-8501$ 石川県石川郡野々市町扇が丘, Division of Environmental Eng., Kanazawa Inst. of Tech., Ishikawa-gun, Ishikawa, 921-8501 
(2)および式 (5)で示さ机る。ただし，式 (1)，式 (2)の反 応は中性付近で容易に進行するが, $\mathrm{pH}$ が $3 \sim 4$ になる ときわめて緩慢な反応となる。また，この際土中水の溶 存酸素が消費される. つざに, 生化学的酸化には主に硫 黄酸化細菌によるものと鉄酸化細菌によるものがある? 好気的条件化で硫黄酸化細菌の作用により式 (3)の反応 が進行し，硫黄は硫酸イオンに酸化され $\mathrm{pH}$ が 4 付近ま で低下する。つぎの段階で鉄酸化細菌が活動を始める。 式 (1)，(2)によって生成した 2 価鉄イオンが鉄酸化細菌 によって酸化を受けると式 (4)の反応が起こり，3 価鉄が 生成される.この反応には式 (5)で化学的に生成する 2 価 鉄も関与するので式 (4) 放よび式 (5)の反応は相乗的に進 行する。また, 溶出水 $\mathrm{pH}$ は固相試料中の黄鉄鉱含有量 だけでなく,黄鉄鉱の酸化により発生する硫酸を中和する 能力を有卞る方解石 $\left(\mathrm{CaCO}_{3}\right)$ 含有量にも依存する。

\section{$3 \cdot 1$ 酸性堆積軟岩の成因}

\section{3 実験材料および室内試験方法}

実験に先立ち，酸性堆積軟岩の成因についての手がか りを得るために，FE 型走查型電子顕微鏡（日立製作所 S-4100 型，二次電子分解能 $1.5 \mathrm{~nm} ）$ による形態分析 行った。Fig. 1左写真は地すべり発生現場で以前に採取 した風化途上にある酸性堆積軟岩砕片表面に露出した珪 藻遺䯝である。文献 9)には生体鉱物作用により珪藻の 核環内に数 $\mu \mathrm{m}$ の大きさの黄鉄鉱が形成されることが報 告されている。Fig. 1右写真は珪藻遺骸中に形成された 黄鉄鉱顆粒であると考えられる。号石川県能登地方には第 三紀系の代表的な堆積土層として珪藻土が広く分布して 打り，穴の成因を探る上で重要な手がかりとなる。

\section{$3 \cdot 2$ 風化過程にある岩の化学的特性}

石川県の河北郡津幡町内の道路新設工事現場で採取し た岩（採取徯実験室内で，直射日光を避けビニール製の 袋に保存）を砕き，一辺約 $5 \mathrm{~cm}$ の立方体の塊に分け，さ らに只の試料を細かく砕き $0.105 \mathrm{~mm}$ ふるいを通過し， $105^{\circ} \mathrm{C}$ で炉幹燥したもの (以下，土試料）をデシケータ 内に保存した。各試料に対して $\mathrm{pH}$, 硫酸イオン含有量 および黄鉄鉱含有率を測定した。黄鉄鉱含有率について は, 初めに試料 $1 \mathrm{~g}$ を水 $0.1 \ell$ に膆濁し, 間隙水中の硫酸 イオン含有量を測定し, さらに試料を過酸化水素水处理 7) することで生成した硫酸イオンを合わせた総硫酸イオン 含有量を測定し,この差を黄鉄鉱由来の硫酸イオン量と し，土の単位重量市たりの黄鉄鉱含有率を求めた。ここ で, $\mathrm{pH}$ は地盤上学会基準 ${ }^{10)}$ に準じてガラス電極法, 硫 酸イオン濃度はイオンクロマトグラフ法を採用した。

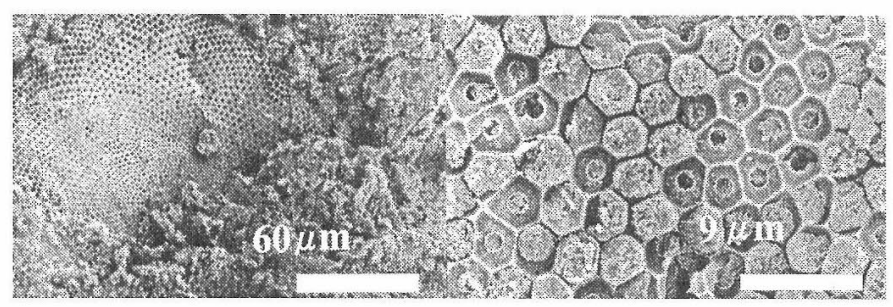

Fig. 1. SEM photographs of diatom remains and pyrite granules observed in the acidifying sedimentary soft rock. $(5 \mathrm{KeV}$, left $\times 300$, right $\times 2000)$

\section{$3 \cdot 3$ 黄鉄鉱および硫黄の生化学的酸化}

生化学的黄鉄鉱，硫黄打よび鉄酸化現象を確認するた め，これらに関与する細菌群の活性化を試みた．Table I に示す培地 $0.1 \ell$ を $0.2 \ell$ 三角フラスコ内で, オートクレー ブにて $121^{\circ} \mathrm{C} ， 15$ 分間滅菌した。これに，化学的特性試 験に使用した土試料 $1 \mathrm{~g}$ 量秤量し懸濁させた。 $30^{\circ} \mathrm{C}$ 恒 温室内で，100rpm の一定速度で旋回培養を行った．時 間とともに硫黄酸化培地は白色に，鉄酸化培地は赤褐色 に憙濁した。この培養䯚濁液を後の奏験に用いた。

生化学的黄鉄鉱酸化に関しては前報引で確認した。ま ず, 生化学的硫黄酸化現象を裏付けるため, 残留塩素を 脱気处理した水道水 $0.1 \ell を 0.2 \ell$ 三角フラスコに 2 個用 意し，㐒れぞれ化学的特性実験に用いた土試料 $1 \mathrm{~g}$ を添 扸し，一方を非滅菌試料，他方はオートクレーブにより 対照用滅菌試料とした。この試料 $30^{\circ} \mathrm{C} の$ 恒洫室人で, $100 \mathrm{rpm} の$ 一定速度で旋回培養し，一定期間ごとに硫酸 イオン濃度と $\mathrm{pH}$ を測定した結果, 滅菌する前の風乾状 態試料に黄鉄鉱の生化学的酸化に寄与する一連の細菌群 が存在する可能性が認められた。しかし, 初期 $\mathrm{pH}$ が 4 と低かったため，硫酸イオンの生成反応が（3）よよ るものか式 (5)によるものかは明らかにできなかっだ兄 こで，市販の黄鉄鉱（高純度化学研究所製，99\%以上） および硫黄粉末（ナカライテスク社製，化学用）を用い て, 硫黄酸化細菌による硫黄酸化の可能性および培地の $\mathrm{pH}$ が生化学的硫黄酸化能に与光影響, すなわち最適 $\mathrm{pH}$ を検討するための実験を行った。培地条件を Table II， Case- 1 に示す. $\mathrm{pH}$ は $0.1 \mathrm{~mol} \cdot \ell^{-1}$ の塩酸抢よび $\mathrm{pH}$ 緩 衝剤である HEPES を用いて $\mathrm{pH}$ 初期設定值を保持する ように調整した。これらの試料老 $30^{\circ} \mathrm{C} の$ 恒温室内で $100 \mathrm{rpm}$ の速度で旋回培養党行い, 所定時間に上澄みの $\mathrm{pH}$ と硫酸イオン濃度を測定した。

\section{$3 \cdot 4$ 生化学的鉄酸化}

鉄酸化細菌の存在を裏付けるため, 鉄酸化培地 $0.2 \ell$

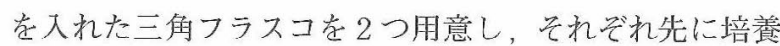
させた鉄酸化細菌懸濁液 $5 \mathrm{~cm}^{3}$ 入れ，一方を非隇菌試 料, 他方はこの試料をオートクレーブにより対照用滅菌 試料とした。この試料を $30^{\circ} \mathrm{C}$ 恒温室内で $100 \mathrm{rpm}$ の速 度で旋回培養を行い，所定時間に上澄みの 2 洒鉄と 3 価 鉄の浱度を吸光光度法により測定, $\mathrm{pH}$ を为ラス電極法 により測定した。つぎに，培地の $\mathrm{pH}$ が鉄酸化細菌群の 酸化能に与光る影響，すなわち最直 $\mathrm{pH}$ を検討するため の実験を行った。培地条件をTable $\Perp$, Case-2 に示す。 Case2-B は予女鉄酸化細菌群を培養した培地 $5 \mathrm{~cm}^{3}$ を添

Table I. Basic culture medium of sulfur and ferrous oxidation.

\begin{tabular}{c|c|c|c}
\hline Sulfur oxidation & {$\left[\mathrm{g} \cdot \ell^{-1}\right]$} & \multicolumn{2}{|c}{ Ferrous oxidation $\left[g \cdot \ell^{-1}\right]$} \\
\hline $\mathrm{NH}_{4} \mathrm{Cl}$ & 0.5 & $\mathrm{NH}_{4} \mathrm{Cl}$ & 0.5 \\
\hline $\mathrm{KH}_{2} \mathrm{PO}_{4}$ & 0.25 & $\mathrm{KH}_{2} \mathrm{PO}_{4}$ & 0.25 \\
\hline $\mathrm{MgSO}_{4} \cdot 7 \mathrm{H}_{2} \mathrm{O}$ & 0.1 & $\mathrm{MgSO}_{4} \cdot 7 \mathrm{H}_{2} \mathrm{O}$ & 0.1 \\
\hline Sulfur powder & 10 & $\mathrm{FeSO}_{4} \cdot 7 \mathrm{H}_{2} \mathrm{O}$ & 10 \\
\hline Distiled water & $1 \ell$ & Distiled water & $1 \ell$ \\
\hline
\end{tabular}


加した. $\mathrm{pH}$ は Case1 と同様に調整した。 これらの試料 を $30^{\circ} \mathrm{C}$ の恒温室内で, $100 \mathrm{rpm}$ の速度で旋回培養を行い, 所定時間に上澄みの 2 価鉄と 3 価鉄濃度および $\mathrm{pH}$ を測 定した.

\section{4 実験結果と考察}

\section{$4 \cdot 1$ 風化過程にある岩の化学的特性}

Fig. 2 は風化過程にある土の $\mathrm{pH}$ と黄鉄鉱残存率の関 係を示している、黄鉄鉱残存率とは掘削時の初期黄鉄鉱 含有率と酸化過程にある試料の黄鉄鉱含有率の比である. これらの試料の平均的な初期黄鉄鉱含有率は $1.89 \%$ であ った. 黄鉄鉱残存率が $70 \%$ 以下では黄鉄鉱含有量が減少 するにつれて $\mathrm{pH}$ も低下していることがわかる。

Fig. 3 は土中の硫酸イオン含有量と $\mathrm{pH}$ 試験值の関係

Table II . Culture medium condition of pyrite, sulfur and ferrous oxidation.

\begin{tabular}{c|c|c|c}
\hline Case & Initial $\mathrm{pH}$ & $\begin{array}{c}\text { sterilized or } \\
\text { non-sterilized }\end{array}$ & $\begin{array}{c}\text { Culture }\left(1 \mathrm{~g} \cdot \ell^{-1} \text { in tap }\right. \\
\text { water })\end{array}$ \\
\hline \hline 1-A & $2,2.5,3,3.5,4,5,6$ & non-sterilized & Sulfur powder \\
\hline $1-\mathrm{B}$ & $2,2.5,3,3.5,4,5,6$ & sterilized & Sulfur powder \\
\hline $1-\mathrm{C}$ & $2,2.5,3,3.5,4,5,6$ & non-sterilized & Pyrite \\
\hline 1-D & $2,2.5,3,3.5,4,5,6$ & sterilized & Pyrite \\
\hline 2-A & $2,2.5,3,3.5,4,5,6$ & non-sterilized & $\mathrm{FeSO}_{4}$ \\
\hline 2-B & $2,2.5,3,3.5,4,5,6$ & sterilized & $\mathrm{FeSO}_{4}$ \\
\hline
\end{tabular}

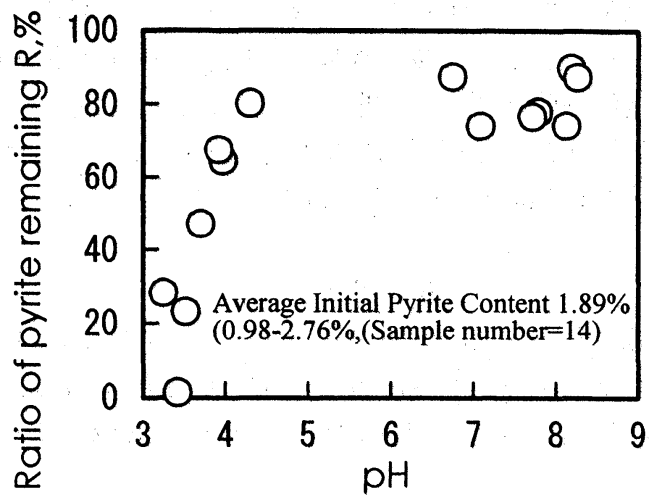

Fig. 2. Ratio of pyrite remaining of soil in the weathering process.

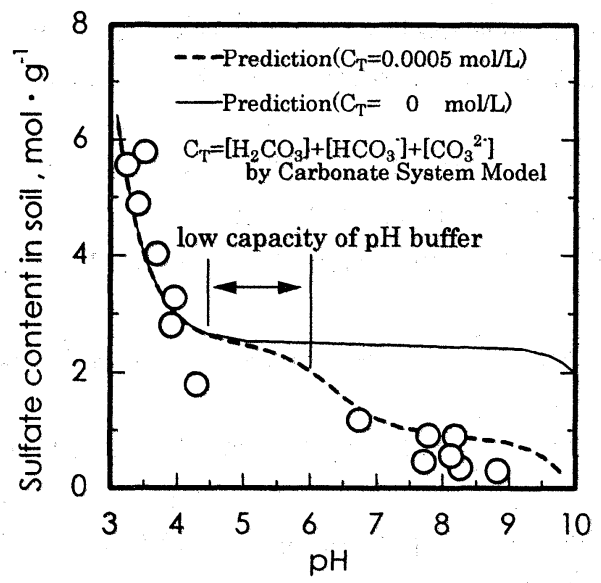

Fig. 3. Relationship between sulfate in soil water and $\mathrm{pH}$.
を示している，硫酸イオン含有量が大きくなるほど $\mathrm{pH}$ が低くなる。ただし，pHの低下が黄鉄鉱の酸化に伴う 式 (1)の反応によるものと考えると，この図より $\mathrm{pH}$ が初 期黄鉄鉱含有率の大小に依存しないこと，また， $\mathrm{pH} 4.5$ 〜 6の間に試料がないという特徴が確認できた。これは， 土自身の $\mathrm{pH}$ 緩衝能のみならず土の $\mathrm{pH}$ の測定条件が大 気に開放系であり，炭酸イオンの緩衝能に大きく左右さ れるることで説明できる。そこで，炭酸塩水溶液系 ${ }^{11)}$ 仮定したモデル解析を行い実験結果と比較した結果，全 炭酸塩濃度 $\mathrm{C}_{\mathrm{T}}$ が $0.5 \mathrm{mmol} \cdot \ell^{-1}$ の場合に実験時の $\mathrm{pH}$ と 硫酸塩含有量の関係を良好に再現でき，このとき $\mathrm{pH}$ が 4.5 ～6の間では $\mathrm{pH}$ 緩衝能が低いことがわかる.

\section{$4 \cdot 2$ 生化学的黄鉄鉱および硫黄酸化}

Fig. 4 は経過時間とともに変化した実測 $\mathrm{pH}$ と硫酸イ オン濃度の関係を示している。最終的に黄鉄鉱を入れた 培地では硫酸イオンが確認され，とくに $\mathrm{pH} 2$ ～3.5 では 硫酸イオンが $1.5 \sim 3.5 \mathrm{mmol} \cdot \ell^{-1}$ 確認された。また, $\mathrm{pH} 4$ 以上では硫酸イオンがほとんど生成して抢らず，非 滅菌試料と滅菌試料の硫酸イオン濃度を比べると, 生化 学的硫黄酸化が起こり, 式 (3)もしくは式 (5)の反応が進 行したと考えられる。一方, 硫黄粉末を添加した試料で は非滅菌試料と滅菌試料の差がほとんど見られなかった が, $\mathrm{pH} 2$ においてのみ硫酸イオンが顕著に生成され, 約 $2 \mathrm{mmol} \cdot \ell^{-1}$ の差が見られた。しかし， 3 価鉄の蓄積によ り, 式 (5)の反応が起こったと仮定すると, 式 (3)より式 (5)の反応により硫酸イオンが生成された可能性が高い. これらの結果から,生化学的硫黄酸化は $\mathrm{pH} 2.5 \sim 3.5$ で活 性化するが, 硫黄酸化細菌の関与は小さいと考えられる.

\section{$4 \cdot 3$ 生化学的鉄酸化}

以上より, 鉄酸化細菌の関与が重要であることが明ら かとなった，Fig. 5 は 2 価鉄と 3 価鉄の経時変化を表し ている．5日目までは 2 価鉄および 3 価鉄濃度共に大き な変化は見られないが，6日目以降非滅菌試料では 2 価 鉄濃度が低下し 3 価鉄濃度が増加し, $\mathrm{pH}$ も変化し始め た。このとき非滅菌系では初期 $\mathrm{pH}$ が 2.86 であったが， 9 日後には 2.12 に低下していた。この結果から，鉄酸化 細菌が 2 価鉄を 3 価鉄に変化させる式 (4)の反応が起こ り, $\mathrm{pH}$ も低下したと考えられる!ここで, 2 価鉄と 3 価 鉄の量論的不一致は二部の 3 価鉄が水酸化第 2 鉄 $(\mathrm{Fe}$ $\left.(\mathrm{OH})_{3}\right)$ の沈殿として水中から除去されたためである

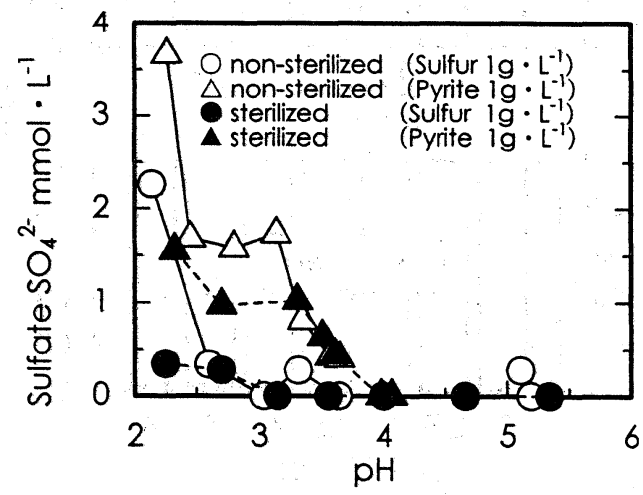

Fig. 4. Effects of $\mathrm{pH}$ on sulfate concentration under different sources of sulfur. 


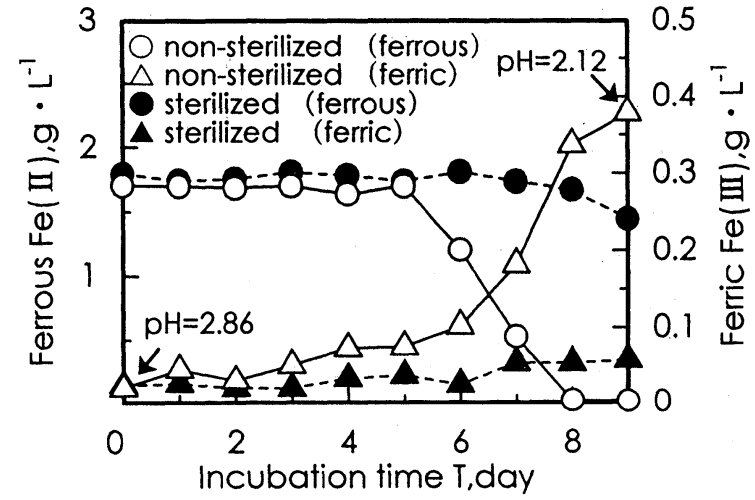

Fig. 5. Variations of ferrous and ferric concentration with time under different sources of sulfur.

Fig. 6 は培地 pH を変化させた場合の 18 日後の総鉄 イオンに占める 2 価鉄および 3 価鉄濃度の割合を示して いる.上段の非滅菌試料では $\mathrm{pH} 2.5 \sim 3.5$ で鉄イオンに 占める 3 価鉄の割合が約 $70 \%$ 前後と顕著になる。また， 下段の滅菌試料では，3 価鉄の生成は見られないことか ら, 式 (4)，(5) の反応の最適 $\mathrm{pH}$ はともに $2.5 \sim 3.5$ で あり, 2 価鉄は 3 価鉄に生化学的に変換されたことがわ かる.

ここで，はじめに $\mathrm{pH}$ が中性付近にある試料が生化学 的酸化に適した $\mathrm{pH}$ 範囲へ化学的に移行する現象につい て考察する. 化学的酸化のみによりこの現象が起こると 仮定すると，長期間を要することが推察される。しかし， 実際には数ヶ月という短期間で酸化が進行すること ${ }^{3)}$ ら，大気に開放な炭酸塩水溶液系とは異なる環境を作り 出すことを念頭に， $3 \cdot 3$ 節と同様に水試料を作成し，初 期 $\mathrm{pH}$ が中性域の土試料を用いて，一定期間（40日間） のかく拌を行い容易に $\mathrm{pH}$ の低下が起こらないことを確 認した上で，かく拌から静置培養へと切り替えた。その 結果, Fig. 7 に示すようにきわめて短期間で溶液の $\mathrm{pH}$ は低下し，硫酸イオンの生成が見られた。すなわち，振 騰系ではフラスコ内が巨視的に均一な炭酸塩水溶液系で

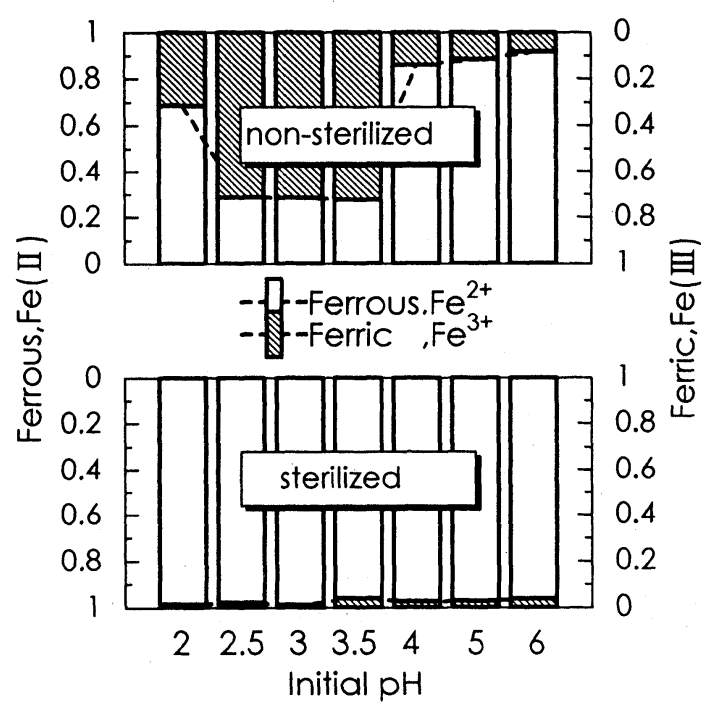

Fig. 6. Ratio of ferrous or ferric for all iron with the oxidation of pyrite after $18^{\text {th }}$.

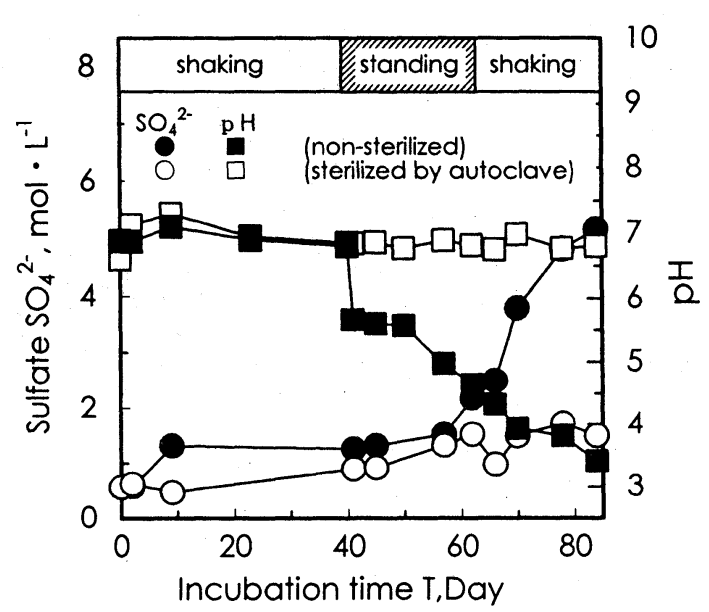

Fig. 7. Variation of sulfate and $\mathrm{pH}$ with time under different methods of agitation.

あるのに対して, 静置系では化学的酸化により生成した 硫酸イオンが土固相近傍に蓄積し, 生化学的酸化に適し た微視的な低 $\mathrm{pH}$ 環境が作り出されたと考えられる.

5 結

言

本研究に打いては, 酸性堆積軟岩の風化過程のメカニ ズムを，化学的作用と，微生物学的作用に分けて実験的 に検証を試みた。まず，酸化過程にある土の化学的特性 から黄鉄鉱含有量が潜在的な酸性化ポテンシャルを推定 する因子であり，土中水の硫酸イオンが土の $\mathrm{pH}$ を決定 する因子であることを明らかにした。つぎに，滅菌試料 と非滅菌試料の $\mathrm{pH}$ および硫酸イオンの濃度変化の比較 検討より，生化学的酸化機構を説明し，硫黄酸化細菌よ り鉄酸化細菌の関与が重要であること, 酸性土の安定処 理の前処理として短期間に生化学的酸化を完了させるた めの最適 $\mathrm{pH}$ は 2.5 〜 3.5 であることを明らかにした。

\section{参 考 文 献}

1）陽田秀道，土木学会論文集，No.617/III-46，213（1999）.

2）佐野博昭，山田幹雄，能澤真周，奥村充司，渡邊康二, 日本材料学会第 3 回地盤改良シンポジウム発表論文集, 41 (1998).

3) 佐野博昭, 山田幹雄, 奥村充司, 能澤真周, 平井裕二, 土木学会論文集, No.687/III-56,95 (2001).

4) 奥村充司, 山田幹雄, 佐野博昭, 小川実通博, 日本材料 学会第 5 回地盤改良シンポジウム発表論文集, 89 (2002).

5 ）廃棄物学会編, “廃棄物ハンドブック”, p.853 (1997) オー 厶社.

6 ) 尾崎哲二, 下垣 久, 塩月隆久, 吉田恒夫, 土木学会論 文集, No.624/III-47, 283 (1999).

7 ) 石坂信行, 神奈川県温泉地学研究所報告, 24 , 第 2 号, 1 (1993).

$8 ）$ 五十嵐敏文, 大山隆弘, 斎藤典之, 応用地質, 42,214 (2001).

9 ) 伊藤和男, 名古屋市環境科学研究所報, 26, 51 (1998).

10）地盤工学会, “土質試験一基本と手引き-”, p.67 (2000).

11）W. Stumm and J. J. Morgan, “一般水質化学”, p.116 （1974）共立出版. 